\title{
Erratum to: High-fiber date pits pudding: formulation, processing, and textural properties
}

Mohammed S. Alamri • Abdellatif A. Mohamed • Shahzad Hussain

Published online: 2 October 2014

(C) Springer-Verlag Berlin Heidelberg 2014

Erratum to: Eur Food Res Technol

DOI 10.1007/s00217-014-2216-x

In the original publication, the Acknowledgment has been inadvertently missed. The relevant Acknowledgement is given below.

Acknowledgments The Authors extend their appreciation to the Deanship of Scientific Research at King Saud University for funding the work through the research group project No.: (RGP-VPP-114) i.

The online version of the original article can be found under doi:10.1007/s00217-014-2216-x.

M. S. Alamri $(\bowtie) \cdot$ A. A. Mohamed $\cdot$ S. Hussain

Department of Food Science and Human Nutrition, King Saud

University, P.O. Box 2460, Riyadh 11451, Saudi Arabia

e-mail: abdmohamed@ksu.edu.sa

A. A. Mohamed

e-mail: abdellatif97tas55@yahoo.com 